\title{
Estudo das implicações do espaço ofensivo nas características do ataque no Voleibol masculino de elite
}

\author{
José Miguel de Castro \\ Isabel Mesquita
}

https://doi.org/10.5628/rpcd.08.01.114

\author{
Faculdade de Desporto \\ Universidade do Porto \\ Portugal
}

\section{RESUMO}

O objectivo do presente estudo consiste na aplicação de um modelo zonal de ataque de primeira linha bem como da sua associação com variáveis especificadoras do ataque: o tempo de ataque, o efeito do ataque, o tipo de ataque e a oposição situacional do bloco. Foram analisados 12 jogos de selecções nacionais, com recurso à digitalização de imagens, num total de 518 acções. Recorreu-se ao teste de qui-quadrado, complementado por uma análise de correspondências simples (ANACOR), para se analisar a relação entre as variáveis. A fiabilidade pela percentagem de acordos, complementada pelo Kappa de Cohen, mostrou que os dados são fiáveis enquanto ferramenta científica. A aplicação de um modelo zonal, que especifica funcionalmente as zonas de ataque de primeira linha, evidenciou a tendência das equipas em alargar o espaço de intervenção do ataque, pelo uso preferencial das zonas mais lateralizadas (4a e 2) e pela exploração de zonas intermédias (4b, 3b, 3c), no sentido de destabilizar a actuação do bloco através da criação de superioridade espacial no ataque. $O$ presente estudo reforçou a tendência da utilização privilegiada do tempo 2 de ataque no jogo de alto nível, confirmando o incremento da velocidade nas manobras ofensivas das equipas, bem como o ascendente da eficácia do ataque ao evidenciar o ponto como o efeito mais frequente. O número de blocadores intervenientes na oposição ao ataque adversário mostrou estar associado à velocidade do ataque, sendo que, tendencialmente, quanto mais rápido é o ataque menos blocadores efectivam o bloco.

Palavras-chave: análise do jogo, voleibol, elite, ataque

\begin{abstract}
Implications of offensive spacing in elite male volleyball attack characteristics

The aim of the present study consists in application of a zone attack model of the first line, and in the determination of its association, specifying variables of the attack such as the attack tempo, attack effect, type of attack and situational opposition of the block. We analysed 12 games from national teams, using the digitalisation of images, in a total of 518 actions. An inferential analysis was done to find out the possible relationships between variables using Chi-square test and a simple correspondence (ANACOR). The reliability from percentages of the agreements accomplished for Kappa Cohen statistic showed that the observations are reliable to be used as a scientific tool. The application of a zone attack model, which functionally specifies the zones of attack of the first line, demonstrated the top level teams' tendency in widening the intervention space of the attack, with the preferential use of the more lateral zones ( $4 a$ and 2), and also with the exploration of intermediate zones $(4 b, 3 b, 3 c)$ so as to destabilize the block action, through the creation of space attack superiority. The present study stressed the tendency of the privileged use of tempo 2 of the attack in recent elite level game, confirming the increment of the velocity in the teams' offensive patterns, as well as the increase of the attack efficacy when proving the point as the more frequent effect. The number of blockers intervening was shown to be associated with the velocity of the attack, since, as a tendency, the quicker the attack the less blockers block.
\end{abstract}

Key-words: game analysis, volleyball, top level, attack 


\section{INTRODUÇÃO}

No contexto do jogo de Voleibol é inegável o papel que o ataque sempre assumiu no desenrolar do jogo, demonstrando-se determinante no sucesso competitivo das equipas $(39,55)$. Diferentes estudos realizados, quer antes da alteração do regulamento pela FIVB em 1999(10, 15, 16, 17, 23, 35) quer depois (6, 13, 20, 25, 34, 42, 46), comprovam a importância do ataque no rendimento das equipas, ao mostrarem que constitui a acção mais correlacionada com a vitória. Palao, Santos e Ureña(42), num estudo realizado com 33 jogos das equipas masculinas presentes nos Jogos Olímpicos de Sydney, constataram que as equipas melhor classificadas se distinguiram das restantes, fundamentalmente, pelo rendimento mais elevado ao nível do ataque. Marcelino(34), numa amostra que integrou 70.419 acções referentes a todos os jogos da Liga Mundial de 2005, verificou que o ataque foi o procedimento de jogo que mais poder discriminatório exerceu no resultado do set.

As acções ofensivas podem ocorrer em diferentes momentos do jogo, sendo que no Voleibol as condições de organização das acções distinguem-se em função das particularidades dos diferentes complexos de jogo(37). Sem excluir a importância da análise do jogo ao nível do Complexo II (equipa tem a posse do serviço), constata-se que a ocorrência do ataque é significativamente mais elevada no Complexo I (equipa não tem a posse do serviço)(42), pronunciando-se esta tendência com a alteração do regulamento em 1999. Para, além disso, os estudos comprovam que no Complexo I os atacantes alcançam mais sucesso(1, 43) e jogam mais rápido do que no Complexo II (1). O incremento na utilização do serviço em suspensão(2, 32), apesar do risco de errar aumentar ${ }^{(60)}$, tem vindo a alterar a dinâmica do ataque no Complexo I.

Deste modo, as acções ofensivas assumem características diferenciadas, nomeadamente em função da qualidade da distribuição, do tempo de ataque, dos sistemas defensivos adoptados pelo adversário e da zona por onde é finalizado o ataque(41).

Particularmente, na zona central da rede, os ataques são geralmente efectuados pelos atacantes mais rápidos, designados de centrais, podendo, ser realizados pelos jogadores pontas (ocupam a zona 4 no esquema ofensivo), resultantes de combinações de ataque com o distribuidor. Contudo, a organização ofensiva das equipas tem evoluído com o tempo. Se tempos houveram em que a distribuição era confinada a uma zona restrita, limitando o espaço ofensivo, actualmente assiste-se ao recurso de espaços de organização ofensiva mais vastos o que, concomitantemente, gera maior amplitude nas manobras ofensivas ${ }^{(18)}$. De facto, os estudos mais actuais apontam para uma utilização da rede, no ataque, em toda a sua extensão, com uma incidência elevada nos seus extre-

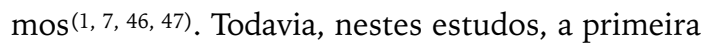
linha de ataque foi dividida em três zonas, em referência ao espaço formal consignado no regulamento de jogo, não espelhando a funcionalidade do ataque. Consequentemente, as dinâmicas dos processos ofensivos, particularmente o espaço e o tempo de ataque, são subjugadas a uma divisão zonal imposta regularmente, desconsiderando a funcionalidade ofensiva do jogo de elite da actualidade.

Com base neste referencial teórico, considerou-se pertinente analisar o espaço de ataque numa perspectiva funcional, no sentido de identificar a sua relação com algumas das variáveis especificadoras desta acção (tempo de ataque, oposição situacional, tipo de ataque e efeito do ataque).

\section{MATERIAL E MÉTODOS}

\section{Amostra}

Foram analisadas 518 acções de ataque pertencentes ao Complexo I. A amostra foi retirada de doze jogos, disputados por quatro selecções nacionais (Portugal, Brasil, Japão e Venezuela) presentes na Liga Mundial 2005 e seis (Portugal, Croácia, Espanha, Itália, Rússia e Sérvia e Montenegro) participantes na Fase Final do Campeonato da Europa de 2005. A selecção da presente amostra foi do tipo não probabilístico intencional e teve como critério o facto das equipas representadas pertencerem a um grupo de voleibolistas de elite (Seleções Nacionais), a disputarem uma competição oficial internacional.

\section{Variáveis}

\section{Zona de ataque}

Em virtude de não existir um modelo zonal que correspondesse, na íntegra, aos requisitos do presente estudo procedeu-se à sua construção. Foram utilizadas duas estratégias de forma a garantir a validação 
de construção e de conteúdo. Inicialmente realizouse uma revisão da literatura com o propósito de identificar diferentes modelos zonais de ataque ${ }^{(4,5}$, $26,33,41,51,53,57)$. As categorias que mais se ajustam ao nosso problema foram encontradas no modelo proposto por Baudin(4), o qual integra 7 zonas. Posteriormente, para se proceder à validação de conteúdo, recorreu-se à aplicação de um estudo preliminar com o propósito de aferir a ajustabilidade das categorias consideradas no modelo de Baudin (4), à ecologia do jogo das equipas em estudo. $\mathrm{O}$ estudo mostrou a necessidade de se restringir o modelo a 6 zonas, decorrente do facto de se constatar que no modelo de Baudin(4), a zona 3a (categorização do presente estudo) dividida em duas, apresentava frequências substancialmente baixas o que justificava a sua junção. Assim, o modelo zonal aplicado (6 zonas, no espaço junto à rede com 9 metros de largura por 3 de comprimento) comporta as seguintes zonas (Figura 1): Zona 4a e 2 - 1,4 metros; Zona 4b - 2 metros; Zona $3 \mathrm{c}-1,3$ metros; Zona $3 \mathrm{~b}-1$ metro; Zona $3 a-1,9$ metros.

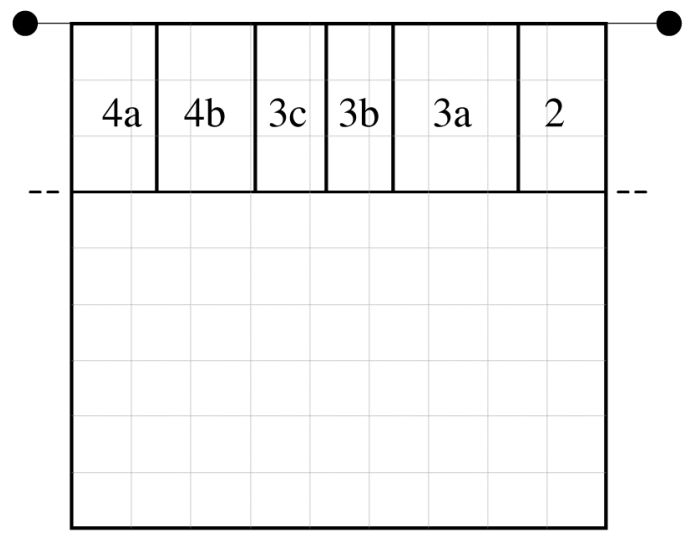

Figura 1. Modelo Zonal de Ataque do Espaço Ofensivo Avançado.

\section{Tempo de Ataque}

No sentido de relacionar o momento de saída para o ataque do jogador atacante e o momento de contacto da bola pelo distribuidor, indicadores passíveis de observação objectiva e que reflectem a velocidade do ataque, estabeleceu-se uma categorização a partir da preconizada por Selinger(51):
Tempo 0: o atacante chega ao ponto de contacto antes do toque do distribuidor.

Tempo 1: o atacante chega ao ponto de contacto simultaneamente, ou logo após, o toque do distribuidor.

Tempo 2: o atacante inicia a corrida de aproximação imediatamente antes ou durante o toque do distribuidor.

Tempo 3: o atacante inicia a corrida de aproximação no momento em que o passe atinge o ponto mais alto da sua trajectória ascendente.

\section{Efeito do Ataque}

Com o propósito de se avaliar o efeito do ataque considerou-se 4 categorias, de forma a distinguir no efeito Continuidade as possibilidades de organização ofensiva induzidas ao adversário. Deste modo foi considerado:

Ponto (P): quando o atacante concretiza ponto em qualquer circunstância: atacando a bola directamente para o solo do campo adversário, contactando o bloco adversário com eficácia e por falta do adversário; Continuidade que permite o contra-ataque (C1): quando a equipa adversária defende e organiza o contra-ataque (mais do que uma opção de ataque);

Continuidade que não permite o contra-ataque (C2): a equipa adversária defende, mas não em condições de organizar o contra-ataque, ou, ainda, quando a bola é devolvida pelo bloco adversário, ficando novamente na posse da equipa;

Erro (E): quando a equipa atacante erra, em qualquer circunstância, resultando em ponto para a equipa adversária.

\section{Tipo de Ataque}

Através da literatura consultada $(33,41,51,59)$ verificamos várias classificações dos tipos de ataque, de acordo com critérios distintos (direcção do ataque, tipo de corrida de aproximação, exploração do bloco, etc). No presente estudo, utilizou-se como critério de base a exploração do bloco, porquanto esta variável é caracterizadora do sucesso do ataque nas equipas de alto nível(11). Complementarmente, em cada uma das categorias considerou-se a direcção do ataque, por ser um indicador importante no estudo das tendências ofensivas das equipas ${ }^{(9,59)}$. Deste modo, foi considerado: (1) Ataque sem toque no bloco (STB): 
Ataque forte e Ataque colocado; (2) Ataque com toque no bloco (CTB): Block-out (quando o atacante joga para as extremidades da mão do blocador) e Costura (consiste em atacar a bola para o espaço entre as mãos dos blocadores, o que pressupõe a existência de, pelo menos, dois blocadores).

\section{Oposição situacional do bloco}

Nesta variável foi considerado o número de blocadores intervenientes na acção de bloco, podendo existir teoricamente entre nenhum a três blocadores.

Considerou-se duas possibilidades para a situação em que não existe bloco: ODist - (Quando os blocadores não efectivam o bloco, em virtude do distribuidor colocar o atacante em condições excelentes de finalização, não permitindo aos blocadores chegar a tempo de o efectivar); 00pção (Quando os blocadores não blocam pelas condições de ataque serem precárias, indicando reduzida ofensividade).

\section{Procedimentos de recolha dos dados}

A recolha dos dados foi realizada em diferido, através do vídeo com recurso à digitalização de imagem. Para cada uma dos jogos construiu-se um modelo topográfico através do programa Pinacle Studio Plus versão 9.3, de modo a analisar com objectividade e precisão as distintas zonas de ataque. Foi mantida em todos os jogos a perspectiva de topo, ou seja, a visualização do campo longitudinalmente, tendo-se analisado a equipa que se encontrava do lado da câmara, no sentido de se obter maior objectividade e precisão na recolha dos dados.

\section{Procedimentos estatísticos}

Recorreu-se à estatística descritiva habitual para se obter as frequências e respectivas percentagens. Para testar a associação entre os diferentes parâmetros de análise utilizámos o Qui-quadrado $\left(\chi^{2}\right)$ de Pearson em tabelas de contingência e o $V$ de Cramer. Nos casos em que mais de $20 \%$ das células apresentavam valores inferiores a 5, recorremos ao teste de Monte Carlo, que permite obter a probabilidade exacta. O nível de significância considerado foi de 5\%. Complementouse o estudo do Qui-Quadrado pela aplicação de uma análise de correspondências simples (ANACOR), recorrendo-se à normalização simétrica para facilitar a visualização das relações entre as variáveis.

\section{Fiabilidade da observação}

Na perspectiva de verificar a consistência das observações verificamos a percentagem de acordos intraobservador (as duas observações ocorreram com um intervalo superior a 15 dias) e inter-observador. Foram observadas 143 acções (20\% do total da amostra), valor acima do valor mínimo aceitável de $10 \%$ estipulado pela literatura (54). Os resultados obtidos mostraram percentagens de acordos acima dos limites mínimos apontados, ou seja, 80\% (56). O valor mínimo encontrado foi de $95,8 \%$ na variável tipo de ataque (fiabilidade inter-observador) e o valor máximo de $100 \%$ na variável efeito do ataque (inter-observador) e nas variáveis zona de ataque e oposição situacional do bloco (intra-observador e inter-observador). No sentido de excluir a possibilidade de existirem acordos devido ao acaso, aplicou-se a estatística Kappa de Cohen. Os valores registados situaram-se entre 0,97 e 1 na fiabilidade intra-observador e entre 0,92 e 1 na fiabilidade inter-observador, substancialmente acima dos valores de referência considerados elevados pela literatura, $(0,75)(19)$. Os valores obtidos, em ambos os procedimentos, mostram ser fiáveis para serem utilizados como ferramenta científica.

\section{RESULTADOS}

Associação entre a zona de ataque e o tempo de ataque O tempo de ataque mais utilizado foi o tempo 2 $(54,1 \%)$, seguido do tempo $1(33,4 \%)$. Apesar do tempo 0 apresentar uma percentagem de ocorrência irrisória $(2,1 \%)$, foi notória a tendência da generalidade das equipas em jogar rápido, sendo que o $3^{\circ}$ tempo foi utilizado apenas em situações de recurso $(10,4 \%)$. Contudo, ao analisarmos os dados de Sousa et al. (53), num estudo com 3 equipas de elite (Brasil, Cuba e Itália) em que o autor analisou os tempos de ataque ocorridos no complexo I, verificase que o $3^{\circ}$ tempo foi o mais utilizado, com uma frequência de $68 \%$. Esta era uma tendência antes das alterações das regras de pontuação e de introdução do libero $(22,57)$.

No que concerne às zonas mais solicitadas, é clara a maior solicitação das extremidades da rede, sendo a zona $4 \mathrm{a}(41,5 \%)$ a que apresenta uma frequência mais elevada, seguida da zona 2 (19,8\%). Num estudo realizado por Papadimitriou et al.(46), em equipas da primeira divisão masculina do campeonato grego, os resultados convergiram no mesmo sentido, mos- 
Quadro 1. Frequência relativa do tempo de ataque por zona de ataque

\begin{tabular}{|c|c|c|c|c|c|c|c|c|}
\hline & & & \multicolumn{6}{|c|}{ Zona de Ataque } \\
\hline & & & $4 a$ & $4 b$ & $3 c$ & $3 b$ & $3 a$ & 2 \\
\hline \multirow{8}{*}{ 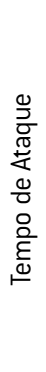 } & 0 & $\%$ tempo ataque & ,0\% & ,0\% & $66,7 \%$ & $33,3 \%$ & ,0\% & ,0\% \\
\hline & & $\%$ zona de ataque & ,0\% & , $0 \%$ & $8,8 \%$ & $8,0 \%$ & , $0 \%$ & ,0\% \\
\hline & 1 & $\%$ tempo ataque & $6,8 \%$ & $22,1 \%$ & $39,5 \%$ & $22,1 \%$ & $7,4 \%$ & $2,1 \%$ \\
\hline & & $\%$ zona de ataque & $5,4 \%$ & $77,8 \%$ & $82,4 \%$ & $84,0 \%$ & $73,7 \%$ & $3,5 \%$ \\
\hline & 2 & $\%$ tempo ataque & $60,7 \%$ & $1,6 \%$ & $2,3 \%$ & $1,3 \%$ & ,6\% & $33,4 \%$ \\
\hline & & $\%$ zona de ataque & $77,6 \%$ & $9,3 \%$ & $7,7 \%$ & $8,0 \%$ & $10,5 \%$ & $90,4 \%$ \\
\hline & 3 & $\%$ tempo ataque & $69,5 \%$ & $11,9 \%$ & $1,7 \%$ & ,0\% & $5,1 \%$ & $11,9 \%$ \\
\hline & & $\%$ zona de ataque & $17,0 \%$ & $13,0 \%$ & $1,1 \%$ & ,0\% & $15,8 \%$ & $6,1 \%$ \\
\hline
\end{tabular}

trando o ascendente da zona $4(39,2 \%$ do total de ataques consumados) na organização ofensiva da equipa. Todavia, a supremacia de utilização do espaço lateral esquerdo da rede é mais evidente no presente estudo, porquanto a dimensão da zona 4a é menor $(1,4 \mathrm{~m})$ do que a dimensão da zona considerada no estudo de Papadimitriou et al.(46) (3 metros, espaço formal imposto pelo regulamento de jogo). Estas divergências encontram justificação no facto do presente estudo ser realizado em selecções nacionais, de elevado nível de rendimento competitivo, sugerindo que a exploração do espaço ofensivo exterior da zona 4 permite aos atacantes ganhar vantagem sobre o bloco adversário; não só, por exigir ao bloco um deslocamento maior, como também por ser a zona onde usualmente se encontra o blocador mais débil (o distribuidor).

A apreciação da análise inferencial permitiu verificar a existência de uma associação significativa ente os tempos de ataque e as zonas de ataque $\left(\chi^{2}=429,180\right.$; $\mathrm{p}=0,000$ ), com uma relação moderada entre as variáveis ( $V$ de $C r a m e r=0,501)$. A maioria das células contribuíram para esta associação ao evidenciaram resíduos ajustados superiores a 2 em valor absoluto. Relativamente ao tempo mais rápido (tempo 0), devido à complexidade que lhe é inerente, apenas é utilizado e com reduzida expressão nas zonas centrais (3c e 3b) (Quadro 1).

O tempo 1 segue a mesma tendência embora com maior expressão na solicitação pelas zonas centrais, já que para além das zonas $3 c$ e $3 b$ também na zona 3a foi mais utilizado do que o esperado. Todavia, constataram-se 13 ocorrências de ataques de $1^{\circ}$ tempo na zona $4 \mathrm{a}$, da responsabilidade quase exclusiva da selecção do Brasil (76,9\%), equipa que tende a jogar cada vez mais rápido, sendo este, indubitavelmente, um indicador de excelência do jogo brasileiro. Tal significa que o tempo 1 de ataque, embora complexo, devido à sua velocidade e precisão de execução, mostra ser extensivamente aplicado no Voleibol de alto rendimento masculino num espaço ofensivo vasto. Estas zonas são cruciais na dinâmica ofensiva, especialmente após recepções de excelente qualidade ${ }^{(46)}$, na medida em que provoca a detenção do blocador central, colocando os atacantes das alas (oposto e ponta) libertos para atacar com oposição facilitada (bloco individual).

Contrariamente o tempo 2, que num passado não longínquo era considerado um tempo rápido não muito aplicado nas zonas laterais do campo(2), mostra ser no Voleibol masculino da actualidade mais utilizado do que seria de esperar, nas zonas laterais do espaço ofensivo de $1^{a}$ linha (4a e 2 ). Claramente este resultado evidencia uma evolução na dinâmica funcional do jogo de ataque, onde a velocidade de jogo começa a generalizar-se a todas as zonas de ataque principalmente à zona $4^{\text {a }}$, na qual tradicionalmente era efectivado um ataque lento. A supremacia do $2^{\circ}$ tempo pela zona 2 é justificada por esta zona ser, funcionalmente, ocupada pelo jogador oposto e por este desenvolver um jogo rápido, combinado com o central $(3,5,11,21,26,33,51)$. De facto, constata-se que desde a década de 90 tem-se vindo a produzir, gradualmente, um jogo de ataque cada vez mais 
rápido, não apenas pelo centro da rede mas igualmente pelas alas, diminuindo drasticamente a utilização do tempo 3 de ataque $(1,7,8,14,31,36,50,61,62)$. Actualmente, o tempo 3 mostra estar a entrar em desuso sendo apenas utilizado com maior expressão na zona 4a, por ser a zona onde em situações ofensivas de recurso é possível incrementar maior ofensividade ao ataque(38). Como referem Katsikadelli(31) e Bellendier(6), a zona 4 é tida como a principal zona de segurança, devido a ser a mais afastada da zona de distribuição no ataque de $1^{a}$ linha, ficando a zona 2 como opção para ataque combinado.

O diagrama (Figura 2) mostra, ao nível espacial a relação entre o tempo de ataque e as zonas de ataque.

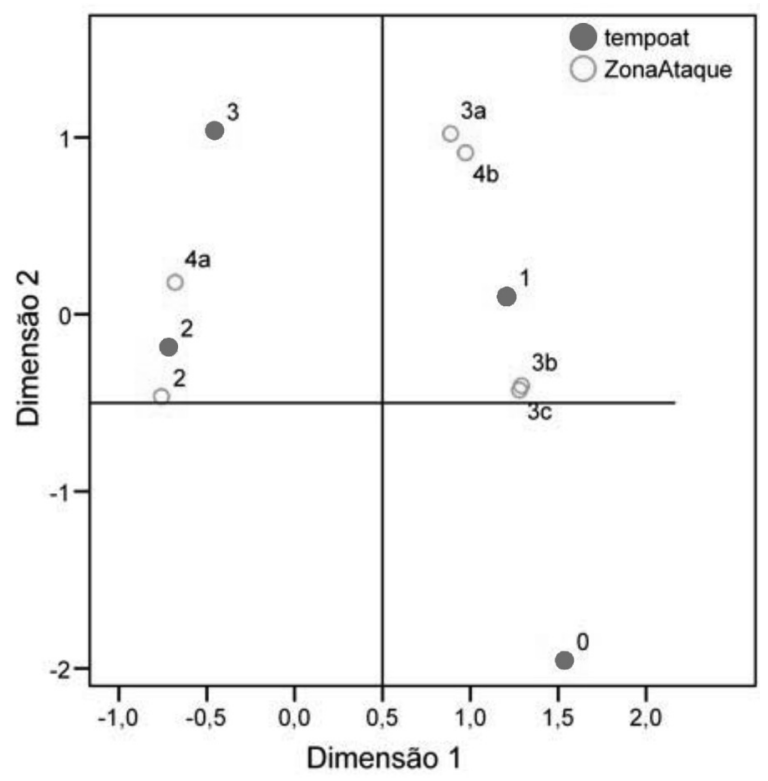

Figura 2. Diagrama de análise de correspondências (ANACOR) entre o tempo de ataque e a zona de ataque.

O tempo 3 está relativamente próximo apenas da zona 4 a e apenas desta zona, sugerindo que o jogo lento é uma solução previsível no jogo de elevado nível de rendimento competitivo. Surge como recurso na zona que permite efectivá-lo com maior segurança, mas não faz parte das soluções ofensivas de excelência das equipas.

O tempo 1 situa-se espacialmente entre quatro zonas, $3 \mathrm{a}, 4 \mathrm{~b}, 3 \mathrm{~b}$ e $3 \mathrm{c}$, mostrando inequivocamente a sua elevada funcionalidade no jogo ofensivo nas zonas centrais da rede e também na zona lateral esquerda interna, sinal da efectivação de um jogo rápido cada vez mais amplo ao nível espacial. A posição do tempo 0 apenas mostra alguma proximidade das zonas $3 \mathrm{~b}$ e $3 c$, reiterando a associação verificado no teste do Qui-quadrado; por ter frequências baixas, graficamente apresenta uma certa distância. O tempo 2 está próximo das zonas 2 e 4 a, mostrando que a efectivação do ataque mais rápido pelas alas assume ser uma regularidade do jogo de elevado nível de rendimento competitivo.

\section{Associação entre a zona de ataque e a oposição situacional do bloco}

O tipo de oposição situacional ao ataque mais frequente foi o bloco duplo $(60,6 \%)$. Rios e Mesquita ${ }^{(48)}$ referenciam que a prevalência do bloco duplo pode ser justificada, por um lado, pela excelente capacidade táctico-técnica dos blocadores e por outro, pela inabilidade do distribuidor em causar estrategicamente desequilíbrios temporais e espaciais no bloco adversário. Destaca-se ainda uma ocorrência substancial de situações de bloco individual (26,9\%), mostrando ser uma regularidade no jogo masculino de elite ${ }^{(1,46}$, 47). No presente estudo o bloco individual mostra possuir ocorrências superiores às do bloco triplo, enquanto que noutros estudos anteriores $(39,47)$ se constatou uma prevalência do bloco triplo relativamente ao bloco individual.

A análise inferencial mostrou uma relação significativa entre a zona de ataque e a oposição situacional do bloco $\left(\chi^{2}=83,271 ; \mathrm{p}=0,000\right)$ de nível fraco $(V$ de Cramer $=0,189)$. Nas zonas de ataque onde se desenvolve um jogo mais rápido (ver quadro 1), o número de blocadores que efectivam o bloco é menor, o que mostra a relevância da velocidade do jogo na fragilização da oposição situacional criada pelo bloco (Quadro 2). Constata-se que o ataque sem bloco, provocado pela elevada ofensividade do ataque, e o bloco individual ocorreram mais do que era esperado, nas zonas de ataque onde se desenvolve um ataque mais rápido ( 3 c e $3 b$ ). Inversamente, o ataque com a oposição de dois blocadores foi superior nas zonas de ataque onde se realiza o ataque menos rápido (4a e 2) e inferior nas zonas centrais $3 \mathrm{c}$ e $3 \mathrm{~b}$ e 4 b, que apesar de não ser central, é utilizada, actualmente, no ataque rápido. 
Quadro 2. Frequência relativa do número de blocadores por zona de ataque

\begin{tabular}{|c|c|c|c|c|c|c|c|c|}
\hline & & & \multicolumn{6}{|c|}{ Zona de Ataque } \\
\hline & & & $4 a$ & $4 b$ & $3 c$ & $3 b$ & $3 a$ & 2 \\
\hline \multirow{10}{*}{ 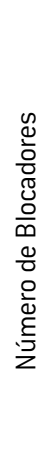 } & 00pção & $\% \mathrm{n}^{0}$ blocadores & $17,6 \%$ & $11,8 \%$ & $23,5 \%$ & $23,5 \%$ & $17,6 \%$ & $5,9 \%$ \\
\hline & & $\%$ zona de ataque & $1,2 \%$ & $3,6 \%$ & $4,3 \%$ & $7,5 \%$ & $13,0 \%$ & ,9\% \\
\hline & 1 & $\% \mathrm{n}^{0}$ blocadores & $26,9 \%$ & $11,5 \%$ & $25,0 \%$ & $14,1 \%$ & $5,1 \%$ & $17,3 \%$ \\
\hline & & $\%$ zona de ataque & $17,4 \%$ & $32,7 \%$ & $41,5 \%$ & $41,5 \%$ & $34,8 \%$ & $23,5 \%$ \\
\hline & 2 & $\% \mathrm{n}^{0}$ blocadores & $46,3 \%$ & $6,5 \%$ & $13,4 \%$ & $6,8 \%$ & $3,1 \%$ & $23,9 \%$ \\
\hline & & $\%$ zona de ataque & $67,6 \%$ & $41,8 \%$ & $50,0 \%$ & $45,3 \%$ & $47,8 \%$ & $73,0 \%$ \\
\hline & 3 & $\% \mathrm{n}^{0}$ blocadores & $62,2 \%$ & $15,6 \%$ & $8,9 \%$ & $4,4 \%$ & $2,2 \%$ & $6,7 \%$ \\
\hline & & $\%$ zona de ataque & $11,6 \%$ & $12,7 \%$ & $4,3 \%$ & $3,8 \%$ & $4,3 \%$ & $2,6 \%$ \\
\hline & Odist & $\% \mathrm{n}^{0}$ blocadores & $45,5 \%$ & $45,5 \%$ & ,0\% & $9,1 \%$ &, $0 \%$ & ,0\% \\
\hline & & $\%$ zona de ataque & $2,1 \%$ & $9,1 \%$ & ,0\% & $1,9 \%$ &, $0 \%$ & ,0\% \\
\hline
\end{tabular}

Do mesmo modo, César e Mesquita(11) num estudo aplicado no Voleibol feminino com selecções nacionais, verificaram que o ataque pela zona 2 regulamentar, tinha como oposição predominante o bloco duplo.

Curiosamente o bloco triplo foi menos utilizado na zona 2 do que seria de esperar, apesar de ser uma zona lateral do campo, onde se desenvolve prioritariamente o ataque de $2^{\circ}$ tempo. Tal pode dever-se ao facto de ser uma zona onde se realiza jogo combinado, com solicitação do oposto e do central, retirando ao bloco a possibilidade de organizar o triplo. Para além disso, como a zona 4 a é a mais utilizada, o bloco nunca a pode descurar, gerindo o risco, e preferindo hipotecar o blocador directo, que raramente tem tempo para formar o triplo, na oposição ao ataque de zona 2.

O diagrama (Figura 3) ilustra espacialmente a relação entre as zonas de ataque e o número de blocadores. A oposição de 1 blocador está inequivocamente posicionada entre as três zonas centrais da rede com maior evidência entre a $3 \mathrm{~b}$ e a $3 \mathrm{c}$. Sendo a zona $3 \mathrm{a}$ coincidente com a zona de distribuição, o ataque rápido é efectivado prioritariamente para o espaço à sua frente, próximo (3b) e afastado (3c), o que provoca maior instabilidade defensiva e, consequentemente, a oposição consumada apenas por 1 blocador. O diagrama mostra ainda ser uma regularidade do jogo masculino de elevado nível de rendimento com-

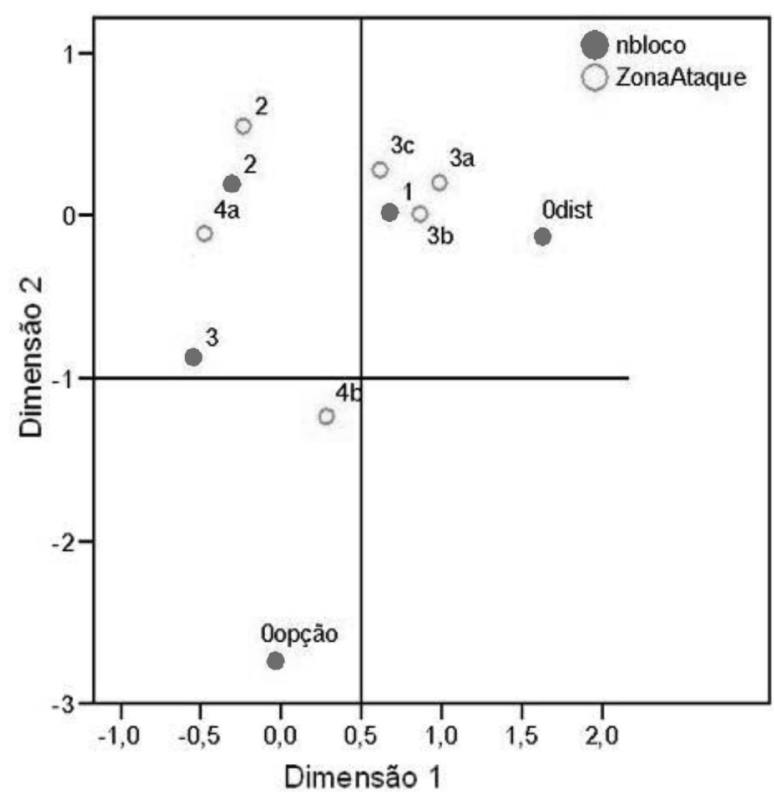

Figura 3. Diagrama de análise de correspondências (ANACOR] entre o número de blocadores e a zona de ataque.

petitivo, a oposição de 2 blocadores nas zonas mais lateralizadas da rede, já que é evidente a sua proximidade das zonas 4 a e 2 . Apesar de serem duas zonas onde se efectiva um ataque relativamente rápido (tempo 2), como já se analisou anteriormente, a oposição situacional através de 2 blocadores, não é 
Quadro 3. Frequência relativa do efeito do ataque por zona de ataque

\begin{tabular}{|c|c|c|c|c|c|c|c|c|}
\hline & & & \multicolumn{6}{|c|}{ Zona de Ataque } \\
\hline & & & $4 a$ & $4 b$ & $3 c$ & $3 b$ & $3 a$ & 2 \\
\hline \multirow{8}{*}{ 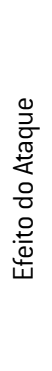 } & Erro & $\%$ efeito ataque & $46,7 \%$ & $9,5 \%$ & $9,5 \%$ & $6,7 \%$ & $3,8 \%$ & $23,8 \%$ \\
\hline & & $\%$ zona ataque & $20,3 \%$ & $18,2 \%$ & $10,6 \%$ & $13,2 \%$ & $17,4 \%$ & $21,7 \%$ \\
\hline & C1 & $\%$ efeito ataque & $44,4 \%$ & $10,0 \%$ & $15,6 \%$ & $11,1 \%$ & $3,3 \%$ & $15,6 \%$ \\
\hline & & $\%$ zona ataque & $16,6 \%$ & $16,4 \%$ & $14,9 \%$ & $18,9 \%$ & $13,0 \%$ & $12,2 \%$ \\
\hline & C2 & $\%$ efeito ataque & $36,3 \%$ & $16,3 \%$ & $11,3 \%$ & $7,5 \%$ & $5,0 \%$ & $23,8 \%$ \\
\hline & & $\%$ zona ataque & $12,0 \%$ & $23,6 \%$ & $9,6 \%$ & $11,3 \%$ & $17,4 \%$ & $16,5 \%$ \\
\hline & Ponto & $\%$ efeito ataque & $40,2 \%$ & $7,5 \%$ & $19,9 \%$ & $9,8 \%$ & $3,9 \%$ & $18,6 \%$ \\
\hline & & $\%$ zona ataque & $51,0 \%$ & $41,8 \%$ & $64,9 \%$ & $56,6 \%$ & $52,2 \%$ & $49,6 \%$ \\
\hline
\end{tabular}

por certo a ideal. Todavia, seria interessante em futuros estudos analisar as condições em que se efectiva o bloco duplo, na medida em que um bloco compacto traz por certo maiores dificuldades ao atacante que um bloco quebrado (espaços entre os dois blocadores, etc.).

O bloco triplo apenas se encontra relativamente próximo da zona $4 \mathrm{a}$ e a maior distância da zona $4 \mathrm{~b}$, o que significa que apenas é efectivado regularmente na zona mais afastada da zona de distribuição. A ausência de bloco perante ataques não ofensivos, (0opção), ocupa uma posição periférica no diagrama, o que demonstra a irrelevância desta situação oposicional ao ataque. Por sua vez, a situação de 0 blocadores, por mérito do distribuidor, apresenta alguma proximidade das zonas $3 \mathrm{~b}$ e $3 \mathrm{a}$, exactamente nas zonas onde decorre o jogo mais veloz.

\section{Associação entre a zona de ataque e o efeito do ataque} $\mathrm{O}$ efeito do ataque que apresenta claramente maior ocorrência é o ponto $(52,7 \%)$, seguindo-se o erro, a grande distância $(18,1 \%)$. Por sua vez, o efeito de continuidade assume valores próximos na possibilidade de permitir a organização do contra-ataque pela equipa adversária, $\mathrm{C} 1$, $(15,5 \%)$ e de não o permitir, C2, (13,8\%). A obrigatoriedade de concretizar ponto no Complexo I, induz as equipas a arriscarem, o que torna a ocorrência do erro relativamente elevada, em relação ao efeito de continuidade.

A análise inferencial mostrou uma relação de independência entre a zona de ataque e o efeito do ataque $\left(\chi^{2}=17,733 ; p=0,101\right)$, tendo um fraco grau de relação ( $V$ de Cramer $=0,107)$. Na zona $3 c$ e na zona $3 b$ é interessante verificar que a seguir ao ponto, o efeito de continuidade que permite ao adversário organizar o ataque (C1) é o mais frequente (14,9\% e 18,9\%, respectivamente) (Quadro 3). Do mesmo modo, no estudo realizado por Sousa (2000), a zona central apresentou os valores mais elevados no efeito ponto. De notar que entre o efeito ponto e a zona $3 c$ existe uma relação de dependência, comprovada pelos valores dos resíduos ajustados $[2,6]$, verificando-se que se pontua mais do que seria esperado nesta zona. A especificação das 3 zonas centrais da rede através do modelo zonal aplicado, permitiu evidenciar a supremacia desta zona em relação às restantes na concretização do ponto. Tal sugere que o ataque rápido com o atacante central afastado do distribuidor, concretizado usualmente na zona $3 c$, mostra ser no Voleibol actual uma estratégia ofensiva profícua, ao destabilizar o bloco pela efectivação do ataque fora do espaço, de partida, dos blocadores. Estes resultados evidenciam a importância da concretização do ataque em diferentes espaços das zonas centrais, no sucesso das equipas de alto nível, de forma a ultrapassar defesas bem organizadas $(3,5,26,44,53)$. Contudo, como se verificou no presente estudo, no Voleibol de elite da actualidade a eficácia do ataque, em termos gerais, não se distingue em função das zonas por onde é consumado, o que significa que, cada vez mais, os jogadores são capazes de atacar com sucesso em espaços diversificados do campo. 
A zona 2, tendo sido a segunda zona de ataque mais solicitada, apresenta valores substancialmente elevados quer do efeito ponto $(49,6 \%)$ quer do erro $(21,7 \%)$. Tal significa que nesta zona, e particularmente no ataque realizado pelo oposto, as equipas assumem o risco de falhar, porquanto a inoperância do ataque, traduzida no efeito de continuidade, resulta em clara vantagem ofensiva para o adversário. O diagrama (Figura 4) ilustra espacialmente a relação entre as zonas de ataque e o efeito do ataque.

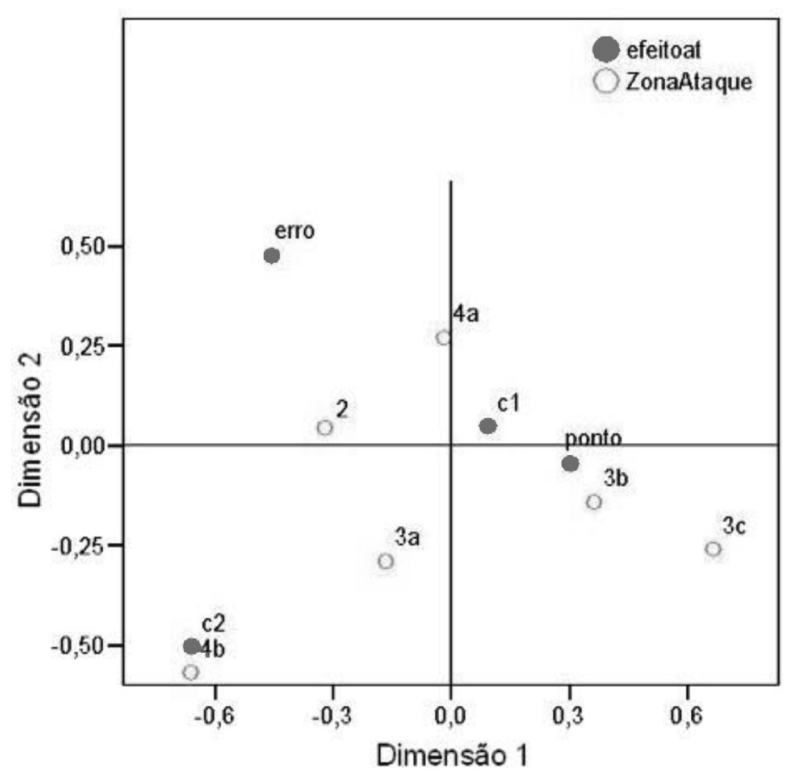

Figura 4. Diagrama de análise de correspondências (ANACOR] entre o efeito do ataque e a zona de ataque.

De uma forma geral verifica-se que não existe proximidade espacial inequívoca entre nenhuma zona de ataque e o efeito do ataque, comprovado na relação de independência obtida pela aplicação do teste de Qui-quadrado. Salienta-se, todavia, uma proximidade espacial evidente entre a zona $4 \mathrm{~b}$ e o efeito de continuidade que não permite ao adversário organizar $\mathrm{o}$ ataque (C2), comprovado nos valores assumidos pelos resíduos ajustados [2,2]. Esta relação de dependência evidencia a importância desta zona (4b) no incremento da ofensividade do ataque, desconsiderada tradicionalmente nos modelos zonais de ataque, porquanto impede o adversário de organizar o ataque mais do que seria esperado.
Associação entre zona de ataque e o tipo de ataque $\mathrm{O}$ ataque forte foi, claramente, o mais solicitado (67\%). O ataque colocado assumiu valores substancialmente inferiores $(12,9 \%)$, seguido do ataque que provoca block-out $(10,5 \%)$ e, por fim, do ataque que é direccionado para o espaço entre as mãos dos blocadores, costura, $(9,6 \%)$.

A aplicação da estatística inferencial permite constatar a existência de uma associação significativa entre a zona de ataque e o tipo de ataque $\left(\chi^{2}=30,262\right.$; $\mathrm{p}=0,009)$, embora de nível fraco ( $V$ de Cramer $=0,132)$. Ocorreu mais do que seria esperado o ataque que provocou block- out pela zona $4 a$, sendo, aliás, por esta zona que este tipo de ataque mais ocorreu (54,1\%) (Quadro 4). Paolini (44) advoga que o indicador de excelência mais importante do atacante consiste na capacidade de provocar blockout. De facto, quando o bloco adversário se encontra mal formado, uma das alternativas mais procuradas pelo atacante é a exploração do bloco, através da utilização estratégica das mãos dos blocadores, resultante do aproveitamento de falhas de marcação do bloco.

O facto da zona $4 \mathrm{~b}$ apresentar valores de ocorrência do ataque colocado superiores ao esperado, pode dever-se à solicitação do ataque combinado, que por qualquer dificuldade de concretização do ataque potente induz os atacantes a optarem em colocar a bola, como solução de recurso; ou, ainda, ao constatarem alguma precariedade no sistema defensivo do adversário, dirigem estrategicamente a bola para espaços vulneráveis. Seria interessante em futuros estudos analisar a relação entre o tipo de ataque utilizado em função das zonas, considerando variáveis especificadoras dos cenários situacionais.

Nas zonas $3 \mathrm{~b}$ e $3 \mathrm{c}$ ocorrem menos do que seria esperado ataques que provocam block-out, o que se pode dever a serem zonas de ataque onde, predominantemente, se aplica o ataque rápido e combinado, não permitindo ao bloco intervir atempadamente sobre a bola.

O diagrama (Figura 5) mostra, ao nível espacial, a relação entre os tipos de ataque e a zona de ataque. Verifica-se que espacialmente as variáveis zonas de ataque e tipo de ataque não formam grupos claros o que evidencia que apesar de existir uma relação de 
Quadro 4. Frequência relativa do tipo de ataque por zona de ataque

\begin{tabular}{|c|c|c|c|c|c|c|c|c|c|}
\hline & & & & \multicolumn{6}{|c|}{ Zona de Ataque } \\
\hline & & & & $4 a$ & $4 b$ & $3 c$ & $3 b$ & $3 a$ & 2 \\
\hline \multirow{8}{*}{$\begin{array}{l}\frac{0}{2} \\
\frac{0}{0} \\
\frac{\pi}{2} \\
\frac{0}{0} \\
0 \\
\stackrel{\circ}{=}\end{array}$} & STB & Forte & $\%$ tipo de ataque & $39,6 \%$ & $8,5 \%$ & $18,3 \%$ & $10,3 \%$ & $3,9 \%$ & $19,5 \%$ \\
\hline & & & $\%$ zonas ataque & $63,9 \%$ & $60,0 \%$ & $75,5 \%$ & $75,5 \%$ & $65,2 \%$ & $66,1 \%$ \\
\hline & & Colocado & $\%$ tipo de ataque & $33,3 \%$ & $16,0 \%$ & $13,3 \%$ & $14,7 \%$ & $6,7 \%$ & $16,0 \%$ \\
\hline & & & $\%$ zonas ataque & $10,4 \%$ & $21,8 \%$ & $10,6 \%$ & $20,8 \%$ & $21,7 \%$ & $10,4 \%$ \\
\hline & СТВ & Block out & $\%$ tipo de ataque & $54,1 \%$ & $8,2 \%$ & $6,6 \%$ &, $0 \%$ & $4,9 \%$ & $26,2 \%$ \\
\hline & & & $\%$ zonas ataque & $13,7 \%$ & $9,1 \%$ & $4,3 \%$ &, $0 \%$ & $13,0 \%$ & $13,9 \%$ \\
\hline & & Costura & $\%$ tipo de ataque & $51,8 \%$ & $8,9 \%$ & $16,1 \%$ & $3,6 \%$ &, $0 \%$ & $19,6 \%$ \\
\hline & & & $\%$ zonas ataque & $12,0 \%$ & $9,1 \%$ & $9,6 \%$ & $3,8 \%$ &, $0 \%$ & $9,6 \%$ \\
\hline
\end{tabular}

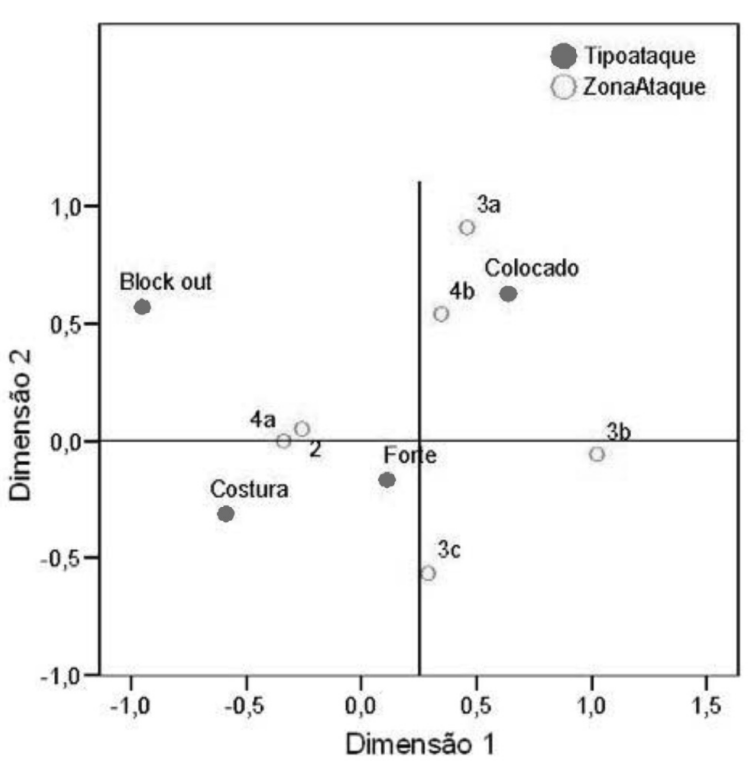

Figura 5 . Diagrama de análise de correspondências (ANACOR] entre o tipo de ataque e a zona de ataque.

dependência global, não é extensiva a todos os tipos de ataque e de zonas. Contudo, constata-se que o ataque colocado está mais próximo da zona $4 \mathrm{~b}$ e, em seguida, da zona $3 \mathrm{a}$, zonas onde o ataque rápido prevalece, tanto por opção como resultante de passes deficitários, induzindo o atacante a utilizar esta variante técnica.

\section{CONCLUSÕES}

O presente estudo reforçou a tendência da utilização privilegiada do tempo 2 de ataque no jogo actual de elevado nível de rendimento competitivo, confirmando o incremento da velocidade nas manobras ofensivas das equipas e o ascendente da eficácia do ataque, ao evidenciar o ponto como o efeito mais frequente. $\mathrm{O}$ bloco duplo continua a ser a situação oposicional que mais ocorre mostrando, que apesar da velocidade de jogo ser cada vez maior, este tende a adaptar-se. $\mathrm{O}$ estudo do espaço ofensivo com aplicação de um modelo zonal, que especifica funcionalmente as zonas de intervenção no ataque de primeira linha, evidenciou a tendência das equipas em alargar o espaço de intervenção do ataque, pelo uso preferencial das zonas mais lateralizadas (4a e 2) e, ainda, pela exploração de zonas intermédias $(4 b, 3 b, 3 c)$, no sentido de destabilizarem a actuação do bloco, através da criação de superioridade espacial no ataque. Destaca-se, ainda, o facto de na zona $4 \mathrm{~b}$, não central, o ataque rápido (tempo 1) ser mais utilizado do que seria esperado, o que evidencia a tendência do incremento da velocidade de ataque, mesmo em zonas menos centrais onde, tradicionalmente, o ataque era mais lento. O número de blocadores intervenientes na oposição ao ataque adversário mostrou estar associado à velocidade do ataque, sendo que, tendencialmente, quanto mais rápido é o ataque menos blocadores efectivam o bloco. Por seu turno, o bloco foi explorado pelo ataque, mais do que seria de esperar, na zona onde mais se ataca (zona 4a) e, prefe- 
rencialmente, em $2^{\circ}$ tempo, evidenciando a importância da táctica individual, particularmente, no ataque efectivado por esta zona.

A necessidade de em futuras investigações atender às particularidades situacionais, onde ocorrem as acções dos jogadores, considerando variáveis que especificam as acções dos jogadores contribuirá, por certo, para um conhecimento mais profundo e contextualizado da performance das equipas e dos jogadores em competição.

\section{CORRESPONDÊNCIA}

\section{Isabel Maria Ribeiro Mesquita \\ Rua Dr. Plácido Costa, 91 \\ 4200-400, Porto, Portugal \\ e-mail: imesquita@fade.up.pt}

\section{REFERÊNCIAS BIBLIOGRÁFICAS}

1. Afonso J, Mesquita I, Palao JM (2005). Relationship between the use of commit-block and the numbers of blockers and block effectiveness. International Performance Analysis in Sport, 5(2): 36-45.

2. Agelonidis Y (2004). The jump serve in Volleyball from oblivion to dominance. Journal of Human Movement Studies, 47:205-213.

3. Asher KS (1997). Coaching Volleyball. Illinois (USA). A.V.C.A. Masters Press.

4. Baudin J (1994). Coaches Manual-Level 1. Fundamentals of Coaching Volleyball. Volleyball Canada.

5. Beal D (1992). Setter training. In A. Kinda (ed.). The Best of Coaching Volleyball, book I: The basic elements of the game: 55-59. American Volleyball Coaches Association.

6. Bellendier J (2002). Ataque de rotación en el voleibol, un enfoque actualizado. Efdeportes - Revista Digital, ano 8, 51. Disponivel em http://www.efedeportes.com/efd60.

7. Bellendier J (2003). Una visión analítico-descriptiva del Mundial de Voleibol Argentina 2002. Efdeportes - Revista Digital, ano 9, 60. Disponível em: www.efdeportes.com/efd60.

8. Bizzochi C (2000). O Voleibol de Alto Nível - Da iniciação à Competição. Fazendo Arte Editorial. S. Paulo.

9. Blain P (2006). Volleyball. De l'apprentissage à la compétition de haut niveaux. Vigot. Paris.

10. Boucher J (1993). Attack systems in international men's volleyball. In Coaches Manual Level 4: 2/1-2/18. Volleyball
Canada. Gloucester, Ontario (Canada).

11. César B, Mesquita I (2006). Characterizations of the opposite player's attack from the opposition block characteristics. An applied study in the Athens Olympic games in female volleyball teams. International Journal of Performance Analysis in Sport, 7(2):13-27.

12. Coleman J (2002). Scouting opponents and evaluating team performance. In Don Shondell; Cecile Reynaud (Eds.). The Volleyball Coaching Bible: 321-346. Champaign, IL: Human Kinetics.

13. Cunha F, Marques A (2003). A eficácia Ofensiva em Voleibol. Estudo da relação entre a qualidade do $1^{\circ}$ toque e a eficácia do ataque em voleibolistas portugueses da $1^{\mathrm{a}}$ divisão. In Investigação em Voleibol. Estudos Ibéricos. I. Mesquita, C. Moutinho e R. Faria (Eds.): 180-189. FCDEF-UP. Porto.

14. Dias C (2004). A Distribuição no Voleibol: Aplicar uma Estratégia Eficaz. Treino Desportivo (24): 51-59.

15. Dottax D (1987). Volley-ball: du smash au match. Éditions VIGOT. Paris (França).

16. Eom HJ, Schutz RW (1992a). Statistical analyses of volleyball team performance. Research Quarterly for Exercise and Sport, 63(1): 11-18.

17. Eom, H.J.; Schutz, R.W. (1992b). Transition play in team performance of volleyball: A log linear analysis. Research Quarterly for Exercise and Sport, 63(3): 261-269.

18. Esteves F, Mesquita I (2007). Estudo da zona de distribuição no voleibol de elite masculino em função do jogador distribuidor e do tipo de passe. Actas do $1^{\circ}$ Congresso Internacional de Jogos Desportivos - Olhares e contextos da performance. Da iniciação ao Rendimento, Revista Portuguesa de Ciências do Desporto, 7 (supl. 1): 36.

19. Fleiss JL (1981). Statistical Methods for rates and proportion ( $2^{\text {nd }}$ Edition). Wiley. New York.

20. Fotia J (2003). Camino al rendimiento: conceptos iniciales en la enseñanza y el aprendizaje de la defensa de campo. Congresso Internacional sobre Entrenamiento Deportivo. Efdeportes - Revista Digital. Disponível em http://www.rfevb.com/formación.

21. Fraser S (1988). Strategies for Competitive Volleyball. Champaign, Illinois (USA): Leisure Press.

22. Fröhner B, Zimmermann B (1992). Evolution des sistemes offensives au niveau international. International VolleyTech, 4: 27-31.

23. Grgantov Z, Dizdar D, Jankovic V (1998). Structural analysis of the volleyball game elements based on certain anthropological features. Kinesiology, 30(1): 44-51.

24. Guerra I, Mesquita I (2003) As regularidades na aplicação do remate por zona 4 em voleibol em função das zonas alvo de ataque. Estudo aplicado no Campeonato do Mundo de cadetes femininos. In Investigação em Voleibol. Estudos Ibéricos: 169-179. I. Mesquita, C. Moutinho \& R. Faria (Eds.). FCDEF-UP.

25. Häyrinen M (2004). Differences between winning and losing teams in men's European top-level volleyball. In P. O'Donoghue \& M. Hughes (Eds.), Proceedings of VI Conference Performance Analysis: 168-177. St. Mary's University College: Belfast.

26. Hebert M (1991). Insights and Strategies for Winning Volleyball. Illinois: Leisure Press.

27. Hebert M (2005). Preliminary Considerations for designing an Ofense. Coaching Volleyball, 22(1): 12-19.

28. Hughes M (2003). Playing patterns of elite and nonelite 
volleyball. International Performance Analysis in Sport, 3(1): 50-56.

29. Hughes M (2004). Performance analysis - a 2004 perspective. International Performance Analysis in Sport, 4(1): 103109.

30. João V, Mesquita I, Moutinho C, Sampaio J (2006). Análise comparativa entre o Jogador Libero e os Recebedores Prioritários na Organização Ofensiva, a partir da Recepção ao Serviço, em Voleibol. Revista Portuguesa de Ciências do Desporto, 5(2): 318-328.

31. Katsikadelli A (1995). Tactical analysis of the attack serve in high-level volleyball. Journal of Human Movement Studies, 29: 219-228.

32. Lee K, Chin S (2004). Strategies to serve or receive the service in volleyball. Mathematical methods operations research, 59:53-57.

33. Lucas J (1985). Pass, Set, Crush. Volleyball Illustrated: 302305. Washington: Euclid Northwest Publications.

34. Marcelino R (2007). Análise da performance táctica no Voleibol de elevado rendimento competitivo. Dissertação de Mestrado. FCDEF-UP.

35. Marelic N, Zufar G, Omrcen D (1998). Influence of some situation-related parameters on the score in volleyball. Kinesiology, 30(2): 55-65.

36. Martinez N, Abreu P (2003). Influencias del rally poit en la preparación de los voleibolistas. Efdeportes - Revista Digital, ano 9, 62. Disponível em http://www.efdeportes.com/efd62

37. Mesquita I (2005). A contextualização do treino no Voleibol: a contribuição do construtivismo. In O contexto da decisão - A acção táctica no desporto: 355-378. Duarte Araújo (Ed.). Colecção Visão e Contextos das Ciências do Desporto. Lisboa.

38. Mesquita I, Marques A, Maia J (2003). A instrução e a estruturação das tarefas motoras no treino do passe de frente em apoio em Voleibol: estudo aplicado ao escalão de iniciados femininos. In Investigação em Voleibol. Estudos Ibéricos: 9-21. I. Mesquita, C. Moutinho \& R. Faria (Eds.). FCDEF-UP.

39. Moutinho C, Marques A, Maia J (2003). Estudo da estrutura interna das acções da distribuição em equipas de Voleibol de alto nível de rendimento. In Investigação em Voleibol. Estudos Ibéricos: 107-129. I. Mesquita, C. Moutinho \& R. Faria (Eds.). FCDEF-UP.

40. Neville W (1990). Coaching Volleyball Successfully. Champaign, Illinois: Leisure Press.

41. Neville W (1994). Attack. In Serve it Up - Volleyball for Life. Mountain View, California: Mayfield Publishing Company.

42. Palao JM, Santos JA, Ureña A (2004). Effect of team level on skill performance in volleyball. International Journal of Performance Analysis in Sport, 4(2): 50-60.

43. Palao JM, Santos JA, Ureña A (2005). Effect of setter's position on the spike in volleyball. Journal of Human Movement Studies, 48(1): 25-40.

44. Paolini M (2000). Volleyball, from young players to champions. Ancona, Itália: Humana Editrice srl.

45. Paolini M (2006). Il Nuovo sistema pallavolo: tecnica, tattica e didattica con esercitazioni pratiche. $3^{\text {a }}$ ed. - Ferriera di Torgiano (PG). Calzetti Mariucci Editori.

46. Papadimitriou K, Pashali E, Sermaki I, Mellas S, Papas M (2004). The effect of the opponents' serve on the offensive actions of Greek setters in Volleyball games. International Performance Analysis in Sport, 4(1): 23-33.
47. Paulo A, Mesquita I (2005). Caracterização do jogo ofensivo em função da zona de distribuição, da zona de ataque e da posição do bloco no side-out. Estudo aplicado no campeonato do mundo de voleibol de 2002. In Pinto, J. (Ed.). Estudos 5, 121-133. Centro de Estudos de Jogos Desportivos, FCDEF-UP. Porto.

48. Rios N, Mesquita I (2004). As regularidades da aplicação do remate por zona 3 em função da oposição situacional. Estudo aplicado em equipas de Voleibol da $1^{\text {a }}$ divisão masculina-A2. In Oliveira, J. (Ed.). Estudos 4: 40-48. Centro de Estudos de Jogos Desportivos. FCDEF-UP. Porto.

49. Rios N (2002). As regularidades da aplicação do remate por zona 3, função da oposição situacional - Estudo aplicado em equipas seniores masculinas da $1^{\text {a }}$ Divisão A2. Estudo monográfico realizado no âmbito da disciplina de Seminário - opção de Voleibol. FCDEF-UP. Porto.

50. Sawula A (1993). Tendencies and perspectives in international volleyball. In Coaches Manual Level 4: 11/1-11/20. Volleyball Canada. Gloucester, Ontario (Canada).

51. Selinger A, Blount J (1986). Arie Selinger's power Volleyball. New York (USA). St. Martin's Press.

52. Silva J, Mesquita I (2006). Characterization for the Zone 2 attack, in relation to the hitters' type in the elite female Volleyball. In Henriette Dance, Mike Hughes (eds), Abstract Book of World Congress of Performance Analysis of Sport, pp. 520

53. Sousa D, Garganta J, Mesquita I (2001): Analysis of the functional structure of the volleyball offensive phase. In Book of abstracts, $6^{\circ}$ Annual Congress of the European College of Sport Science-Perspectives and Profiles, pp. 1244. Colónia, Alemanha, 2001.

54. Tabachnick BG, Fidell LS (1989). Using Multivariate Statistics ( $2^{\mathrm{a}}$ Edição). New York: Haper \& Row Publishers.

55. Ureña A, Del Campo J, Oña Sicilia A (2003). Incidencia de la función ofensiva sobre el rendimiento de la recepción del saque en voleibol. In I. Mesquita; C. Moutinho; R. Faria (Eds.), Investigação em Voleibol. Estudos Ibéricos: 130141. FCDEF-UP. Porto.

56. Van der Mars H (1989). Observer Reliability: Issues and Procedures. In Analysing Physical Education and Sport Education (2a Edição). 53-79. P. Darst, D. Zakrajsek \& V. Mancini (Eds.). Champaign, IL: Human Kinetics.

57. Vasconcelos M (1998). Influências da acção desenvolvida pela atacante central na circulação táctica ofensiva, sobre a organização do bloco adversário - estudo descritivo em equipas de voleibol feminino sénior da $1^{\text {a }}$ divisão. Tese de mestrado. FCDEF - UP. Porto.

58. Viera B (1990). Volleyball, Steps to sucess (Step to sucess activity series). Illinois (USA): A Division of Human Kinetics Publishers, Inc.

59. Weishoff $P$ (2002). Attacking. In The Volleyball Coaching Bible: 199-226. Don Shondell, Cecile Reynaud (Eds.). Champaign, IL: Human Kinetics.

60. Yannis L, Kountouris P, Aggelonidis I, Katsikadelli A (2004). A comparative study of the effectiveness of the Greek national men's Volleyball team with internationally top-ranked teams. International Journal of Volleyball Research, 7(1): 4-9.

61. Zimmermann B (1995). Trends and Future development of top level Men's volleyball. International VolleyTech, 1: 4-11.

62. Zimmermann B (1999). Changes and potential possibilities with the introduction of Libero in men's world class volleyball. The Coach. 1/99: 4-12. 